\title{
STUDIES ON THE TOXICITY OF SARCOCYSTIS
}

\author{
A. M. MandouR* \\ Department of Parasitology, London School of Hygiene and Tropical Medicine
}

THE toxic effects produced by Sarcocystis have been studied by a few workers including Pfeiffer (1890), Knebel (1912) and Awad (1954). The present work was done to study, for the first time, the toxic effects of Sarcocystis kortei of monkeys and $S$. pitymysi of rodents.

\section{MATERIAL AND METHODS}

Material was obtained from a rhesus monkey (Macaca mulatta) infected with $S$. kortei and three harsh-furred rats (Lophuromys flavopunctatus) infected with $S$. pitymysi. One gramme of the infected muscle was homogenised in $9 \mathrm{ml}$ saline solution $(0.85$ per cent. $\mathrm{NaCl})$ to give a 10 per cent. suspension. The homogenate was filtered through surgical gauze to remove debris. The filtrate contained $4-6 \times 10^{6}$ spores per $\mathrm{ml}$. One gramme of uninfected muscle from the same infected monkey was treated in an identical manner to give a 10 per cent. suspension in saline. Material was also taken from the oesophagi of sheep infected with $S$. tenella and was treated similarly to give a 10 per cent. suspension in saline. An antigen was prepared from $S$. tenella of sheep by Awad's technique.

The toxicity of extracts of $S$. kortei and $S$. pitymysi was tested by intravenous inoculation of $1 \mathrm{ml}$ of the extract into two groups of two domestic rabbits each weighing about $1 \mathrm{~kg}$. One control rabbit was given an intravenous injection of $1 \mathrm{ml}$ saline, and another was given an intravenous injection of $1 \mathrm{ml}$ of the suspension of uninfected muscle. Two rabbits were given an intravenous injection of $1 \mathrm{ml}$ of the suspension of $S$. tenella spores and another two were given intravenous injections of $1 \mathrm{ml}$ of the $S$. tenella antigen.

Other toxicity tests were as follows. A rhesus monkey was given an intravenous injection of $20 \mathrm{ml}$ muscle emulsion containing about $120,000,000$ spores of $S$. kortei. Three albino mice were given a subcutaneous injection of $1 \mathrm{ml}$ sheep muscle emulsion containing about $6,000,000 \mathrm{~S}$. tenella spores. Each of another three mice was given an intraperitoneal injection of the same material as was given subcutaneously to the albino mice. Two control mice were given an injection of $1 \mathrm{ml}$ saline. Two brown-hooded rats (Rattus norvegicus) were given an injection of $1 \mathrm{ml}$ muscle suspension containing 4,000,000 S. pitymysi spores by the subcutaneous or intraperitoneal route. Two control rats were given an intraperitoneal or subcutaneous injection of $1 \mathrm{ml}$ saline. An albino mouse, a brown-hooded rat and an albino rat were fed once on minced sheep muscle containing sarcocystis; $1 \mathrm{~g}$ muscle was eaten by the mouse and $2 \mathrm{~g}$ by each rat. The animals were killed $5 \mathrm{hr}$ after feeding, the appearance of their viscera was observed and paraffin sections from the duodenums and stomachs were examined. An albino mouse and a multimammate rat (Mastomys sp.) were fed on rat muscles (mouse $1 \mathrm{~g}$, rat $2 \mathrm{~g}$ ) infected with $S$. pitymysi and were killed $5 \mathrm{hr}$ later and examined similarly. Three young albino rats were submitted to an operation for duodenal biopsy after which $2 \mathrm{ml}$ of a suspension containing 12,000,000 spores of $S$. tenella was injected into the stomach. Three control rats were operated upon in the same way, but they were given inoculations of $2 \mathrm{ml}$ saline.

\section{RESULTS}

The rabbits into which the spores of Sarcocystis pitymysi had been inoculated did not show any abnormal symptoms or abnormal appearances at necropsy, but those that received the spores of $S$. kortei or $S$. tenella, or the antigen of $S$. tenella, were markedly affected and showed toxic manifestations within a few hours. Their respiration became hurried and their ears hot and flushed, the stools became loose and profuse, and the animals lay helplessly at 
one side of the cage with the hind limbs extended postero-laterally as if they were paralysed. These signs were followed by death within 4-12 hr.

Post-mortem examination showed that the stomach and intestine were ballooned, their contents watery and their mucous membranes, as well as the liver, spleen and kidneys, slightly congested. The left ventricle of the heart contained minute clots, or was empty, and the right side of the heart was engorged with blood. The lungs, brain and spinal cord appeared to be normal.

Rodents that had been fed on, or had been given injections of, infected muscle did not exhibit any abnormal signs during life, but at necropsy their digestive tracts were found to be congested.

The three albino rats submitted to laparotomy showed acute gastric dilatation; their stomachs filled more than half the abdominal cavity.

\section{Discussion}

For the first time, the sarcocystin of Sarcocystis kortei has been shown to produce toxic manifestations and death in rabbits. Its effect was similar to that found for other species of Sarcocystis by Laveran and Mesnil (1899), Rievel and Behrens (1904) and others. The main manifestations were severe diarrhoea and collapse. Intravenous inoculation of the suspension of uninfected muscle from the infected monkey produced no ill-effects, showing that the toxin was not present in the body fluids of the rhesus monkey. This finding is explained by the fact that the effect of the toxin becomes apparent only when the cysts rupture. Rupture of the cysts in vivo has been observed by Smith (1901), Scott (1943) and Mandour (1965). Mandour found that macroscopic cysts ruptured within a few minutes on exposure to 1 per cent. lactic acid. It is still not known, however, whether the toxin is an excretory product of the spores (exotoxin) or is a substance present inside the body of the spores (endotoxin) in a zymogen form, which becomes active when released from the disintegrated spores. The toxic effect of the $S$. tenella antigen produced by disintegrating the spores by Awad's method was found to be more powerful than that produced by inoculating the spores themselves, a finding that supports the view that sarcocystin is an endotoxin.

The observation that spores of $S$. kortei from the rhesus monkey are harmless when inoculated intravenously into another rhesus monkey is surprising. However, it seems possible that periodic rupture of sarcocysts produces a sensitisation in susceptible tissues and that later these tissues are affected by an allergic reaction.

The harmlessness of $S$. pitymysi spores to rabbits and laboratory rodents agrees with the findings of Mesnil, Chatton and Pérard (1913), who reported the absence of any toxic effects in rabbits and rodents given intravenous injections of $S$. muris. The absence of sarcocystin from both $S$. pitymysi and $S$. muris may indicate that there is a difference between the sarcocysts of rodents and those of other animals. If there is such a difference, it may indicate that $S$. muris and S. pitymysi, and perhaps other species of Sarcocystis that parasitise rodents, are specific to that group of animals and are neither acquired from, nor infective to, other animals, including man. On the other hand, it may be that further work will reveal that, if species of Sarcocystis that naturally produce a toxin when developing in mammals other than rodents are introduced into rodents, they are able to infect rodents but do not secrete sarcocystin in them.

It has been shown by Teichmann and Braun (1911) and Awad (1954) that sarcocystin is thermolabile, and accordingly no toxic effects are to be expected in man when he eats cooked infected meat. The pharmacological action of sarcocystin requires to be investigated before the effects of this toxin on the different organs and tissues of man and animals can be explained.

\section{SUMMARY}

When a suspension of a rhesus monkey's muscle infected with Sarcocystis kortei spores was injected intravenously into rabbits, the animals showed toxic manifestations similar to those produced by $S$. tenella spores and antigen; they suffered severe diarrhoea, and collapsed 
and died within 4-12 hr. No toxin was found in the neighbouring uninfected muscles of the same infected monkey.

$S$. kortei did not produce toxic manifestations when fed to laboratory rodents or when fed to, or inoculated into, rhesus monkeys. $S$. pitymysi did not produce toxic effects when injected intravenously into rabbits, or subcutaneously or intraperitoneally into rodents.

\title{
REFERENCES
}

Awad, F. I. . . . . . 1954. Ph.D. Thesis, Univ. London.

KNebel, M. . . . . . . . 1912. Zentbl. Bakt. ParasitKde, 66, 523.

Laveran, A., and Mesnil, F. . . 1899. C.r. Séanc. Soc. Biol., 51, 311.

Mandour, A. M. . . . . 1965. Ph.D. Thesis, Univ. London.

Mesnil, F., Chatton, E., ANd Pérard, C. 1913. C.r. Séanc. Soc. Biol., 75, 175.

PFEIfFER, L. . . . . . 1890. Die Protozoen als Krankheitserreger,

Rievel ANd Behrens . . . . . 1904. Zentbl. Bakt. ParasitKde, 35, 341.

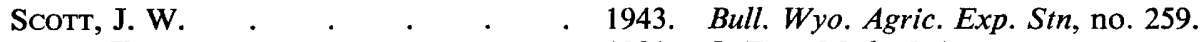

SмITH, T. . . . . . . $\quad$. 1901. J. Exp. Med., 6, 1.

Teichmann, E., and Braun, H. . . 1911. Arch. Protistenk., 22, 351.

\section{IDENTITY AND GLYCOGEN-FERMENTING ABILITY OF LACTO- BACILLI ISOLATED FROM THE VAGINA OF PREGNANT WOMEN}

\author{
Jean G. Wylie and A. Henderson \\ Research Department, Glasgow Royal Maternity Hospital, Rottenrow, Glasgow
}

DESPITE the appearance from time to time of evidence to the contrary, it is still widely thought that Lactobacillus acidophilus is the species of Lactobacillus most frequently found in the vagina in reproductive life, and that, by splitting glycogen, this organism causes the low $p \mathrm{H}$ found in the vagina. The matter is pursued further in this communication.

\section{MATERIALS AND METHODS}

Strains. Two series of cultures of lactobacilli were studied. (1) A series of authentic strains of 11 different species, 1 strain of each, was obtained from the National Collection of Industrial Bacteria (NCIB), the National Collection of Dairy Organisms (NCDO) and the National Collection of Type Cultures (NCTC). One strain was a holotype, 5 were cotypes and 9 were under consideration as the type strains of their species by the Lactobacillus Subcommittee of the International Committee on Bacteriological Nomenclature. These last 9 strains were: L. acidophilus NCIB8690, alternatively American Type Culture Collection (ATCC) no. 4356 (typical); L. buchneri NCIB8007 ( = ATCC4005) (typical); L. bulgaricus NCDO1489 (ATCC11842) (typical); L. casei NCDO161 (ATCC393) (cotype); L. cellobiosus NCDO928 (ATCC11739) (cotype); L. fermentum NCDO1750 (ATCC14931) (typical); L. lactis NCDO1438 (cotype); L. leichmannii NCIB7854 (ATCC4797) (typical); and L. salivarius NCDO929 (ATCC11741) (holotype). Also studied were L. brevis NCDO1749 (ATCC14869) (cotype) and L. helveticus NCIB8025 (ATCC8018) (cotype). (2) A series of 42 wild strains of Lactobacillus were obtained from the vagina of patients attending the Ante-Natal Clinic at the Glasgow Royal Maternity Hospital. Of these patients, 32 had no complaint or objective signs of discharge; a further group of 10 patients had a discharge due to infection with candida. 